\title{
Digital curriculum resources in mathematics education: foundations for change
}

\author{
Birgit Pepin $^{1}\left(\mathbb{D} \cdot\right.$ Jeffrey Choppin $^{2} \cdot$ Kenneth Ruthven $^{3} \cdot$ Nathalie Sinclair $^{4}$
}

Accepted: 27 July 2017 / Published online: 12 August 2017

(C) The Author(s) 2017. This article is an open access publication

\begin{abstract}
In this conceptual review paper we draw on recent literature with respect to digital curriculum resources (DCR); we briefly outline and explain selected theoretical frames; and we discuss issues related to the design, and the use (by teachers and students) of digital curricula and e-textbooks in mathematics education. The results of our review show the following. Firstly, whilst there are some contrasting tendencies between research on instructional technology and research on DCR, these studies are at the same time predominantly framed by socio-cultural theories. Secondly, whilst there seems to be a continuing demarcation between the design(er) and the use(r), there is at the same time an emerging/increasing understanding that design continues in use, due to the different nature and affordances of DCR (as compared to traditional text curriculum resources). Thirdly, there is an apparent weakening of traditional demarcations between pedagogy and assessment, and between summative and formative assessment techniques, due to the nature and design of the automated learning systems. Fourthly, there is an increasing need for understanding the expanded space
\end{abstract}

Birgit Pepin

b.e.u.pepin@tue.nl

Jeffrey Choppin

jchoppin@Warner.Rochester.edu

Kenneth Ruthven

kr18@cam.ac.uk

Nathalie Sinclair

nathsinc@sfu.ca

1 Technische Universiteit Eindhoven, Eindhoven, The Netherlands

2 University of Rochester, Rochester, USA

3 University of Cambridge, Cambridge, UK

4 Simon Fraser University, Burnaby, Canada of interaction associated with the shift from static print to dynamic/interactive DCR, a shift that has the potential to support different forms of personalised learning and interaction with resources. Hence, we claim that DCR offer opportunities for change: of understandings concerning the design and use of DCR; of their quality; and of the processes related to teacher/student interactions with DCR-they provide indeed the foundations for change.

Keywords Digital curriculum resources $\cdot$ Curriculum materials/resources · e-Textbooks · Curriculum · Curriculum design(er) $\cdot$ Curriculum use(er) $\cdot$ Teacher/ student interaction with curriculum resources

\section{Introduction}

In this special issue we examine issues related to e-textbooks and other types of DCR in mathematics education: their analysis and design; their interaction with and use by teachers and students; their use in/for mathematics teacher education (in particular in-service education); and, theoretical reflections related to such studies. It is important to investigate their features, and in which ways they influence, afford, or indeed may transform, particular educational processes and practices; and which theoretical (and/or methodological) considerations and concerns might be linked to these "new" materials.

Internationally, teachers increasingly rely on digital resources, including open educational resources (OERs), to build their mathematics curriculum. Whilst there is an abundance of DCR, teachers often experience difficulties in evaluating their quality, and appropriating/integrating them for/in their instruction in a systematic and meaningful manner. At the same time curriculum resources, 
including digital materials, are known to be key tools for teachers. Moreover, in many countries (e.g., France, The Netherlands, United Kingdom, United States), teachers are increasingly encouraged to (re-) design the curriculum in planning their instruction. One of the concerns arising is about the coherence of their work with DCR (Confrey 2016), whereas before (especially with new reform textbooks) the concern had been on fidelity to the intended curriculum.

Other agents, such as students and teacher educators, also interact with DCR in the course of their work. Various kinds of DCR are now extensively used, sometimes in addition to, or as part of, a wider set of traditional curriculum materials (Remillard 2005) and teaching resources (Adler 2000).

Hence, we note that there is a profusion of DCR now available on the web, and that such digital materials can be considered important, in particular for teacher lesson preparation and classroom instruction, and for pupil learning. There is potential for these materials to provide stimulating and meaningful learning experiences for students, and motivating opportunities for teacher collaborative learning, including the enhancement of teachers' design capacity.

The objective of this special issue is to investigate the ways in which DCR (e.g. e-textbooks and other digital mathematical curriculum materials) may influence (or transform) educational processes and potentially bring about new educational dynamics. We are particularly interested in research on how teachers select, draw from, transform, etc. DCR as they design instruction, and to what effect. The scholarly/scientific significance of the special issue is to develop a better understanding of the quality and design, implementation and interactions of/with DCR at the school level. Much research effort has gone into investigations of traditional curriculum materials (e.g., textbooks; teacher guides; etc.), and of educational technology resources (e.g., calculators). At the same time new DCR have been characterised as being potentially transformative. This special issue extends the recent focus on DCR (e.g., Bates and Usiskin 2016; Choppin and Borys 2016; Gueudet et al. 2016; Pepin et al. 2016), which has addressed the following topics: the development of smart or digital textbooks; the ability to customise or individualise within digital environments, including the kinds and impact of embedded assessment systems that may switch the locus of control from teachers to digital programmes; digital resources collectively developed by teachers, with potential impact on coherence and patterns of uptake; the appropriation of digital resources by teachers and students. In this special issue, we explicitly recognise and build on this research, in order to establish theoretical framing for this work and to hopefully spur broader empirical research efforts. Attempts to realise the promise of DCR—like that of instructional technology-will be influenced by many factors that impact their actual design and use.
While a plethora of DCR have been developed and disseminated-some highly publicised (e.g., Khan Academy) and some the result of significant capital investment (e.g., large publishers' efforts) - there has been relatively little theoretical or empirical work on the development and use of DCR, particularly vis-à-vis traditional curriculum materials. Hence, our goals for this special issue are to provide a frame for future research in terms of:

1. Distinguishing research on DCR from research on instructional technology; and

2. Establishing the current state of empirical and theoretical research on the design and use of DCR.

For this conceptual review paper, we have drawn on a wide range of recent work in the field of digital curriculum resources, materials and programmes; in particular, on recent studies that were presented at ICME 2016 and CERME 2017. This work examines both the design of such materials and participant (e.g. teacher, student) interaction with them. The intention is to "set the scene" for the studies reported in this special issue, and in that respect contribute to the goals set out above.

In terms of the structure of this paper, after this introduction (Sect. 1) we outline (in Sect. 2) our theoretical framing of DCR, of analysis and design of DCR, and of teacher/student interactions with DCR. Section 3 reports on issues concerning the design of DCR, and Sect. 4 reports on teacher/ student interactions with DCR (with or without traditional materials) in and out of school. ${ }^{1}$ In the latter we examine, firstly, the ways in which teachers interact with and use DCR in/for their mathematics instruction: (a) individually, e.g., for lesson preparation (T-DCR); (b) collectively, e.g., in teacher learning and professional development (T-T-DCR); (c) collectively, when they work with students in class (T-S-DCR). Secondly, we study how students use DCR, in particular the scaffolding supports provided in digital learning environments: (a) individually when working with such materials in class or at home (S-DCR); or (b) collectively, e.g., in peer groups (S-S-DCR) (where T stands for teacher, and $\mathrm{S}$ for student).

\section{Theoretical framing}

In this section we discuss frameworks developed and used for the analysis and design of DCR, and for their "use" by

\footnotetext{
1 Whilst acknowledging that "design" and "use" processes often blend into each other, and of course "use" can inform "design", we have nevertheless decided in this paper to separate the two, in order to explore the boundaries.
} 
mathematics teachers and students. The first part explores and defines what is meant by "digital curriculum materials/ resources/programmes" (DCR); the second addresses the analysis and design aspect; and, the third focusses on the "use" and interaction aspect.

\subsection{What do we mean by "digital curriculum materials/ resources/programmes" (DCR)?}

Over the past decade there have been numerous research studies investigating the use of digital technologies and of digital resources for mathematics education (e.g., ClarkWilson et al. 2014, 2015; Drijvers et al. 2016; Ruthven et al. 2009). It has been claimed (e.g., by Ruthven 2017) that the "new media do not simply replicate the functionality of the old with increasing efficiency...; (but) they make possible qualitatively different forms of interaction between user and medium, based - for example — on the introduction of new types of user interface or on the provision of instantaneous feedback on user actions" (p. 2). We claim that this is likely to be true for DCR. However, in terms of teachers'/ students' interactions with those "tools", the question as to whether there is a useful distinction to be made between digital technologies on the one hand, and resources or curriculum materials on the other, needs to be addressed. For example, Aldon (2010) queries whether a handheld calculator can be considered as a mathematical tool, which can then become an instrument [in Trouche's (2004) sense] when it is used, or whether it is part of the teacher's and the students' set of digital resources, to become a document [in Gueudet and Trouche's (2009) sense]. Ultimately, of course, Aldon was free to choose whether to frame his research in terms of the instrumental approach alone, or whether to incorporate the further elaboration introduced by the documentational approach; but such a decision about how to theorise the object of study influences the research questions that can be posed about it and the terms in which these can be answered.

In terms of distinguishing research on DCR from research in digital technologies, we see the main differences as being the particular attention that the former pays to:

1. The aims and content of teaching and learning mathematics;

2. The teacher's role in the instructional design process (i.e., how teachers select, revise, and appropriate curriculum materials);

3. Students' interactions with DCR in terms of how they navigate learning experiences within a digital environment;

4. The impact of DCR in terms of how the scope and sequence of mathematical topics are navigated by teachers and students;
5. The educative potential of DCR in terms of how teachers develop capacity to design pedagogic activities.

Although "curriculum materials" 2 is an elastic termranging from one-off worksheets to a full-blown curriculum scheme/programme-we focus here on curriculum materials that are programmatic in concern: specifically, organised systems of digital resources in electronic formats that articulate a scope and sequence of curricular content. It is the attention to sequencing — of grade-, or age-level learning topics, or of content associated with a particular course of study (e.g., algebra) - so as to cover (all or part of) a curriculum specification, which differentiates DCR from other types of digital instructional tools or educational software programmes. Thus, research on the design and use of DCR is distinct from the broader literature on instructional technology, though clearly there is some overlap. Of course, DCR make use of these other types of tool and software: indeed, what differentiates them from pre-digital curriculum programmes is that they are made accessible on electronic devices and that they often incorporate the dynamic features of digital technologies.

\subsection{Theoretical framing of the design of DCR}

We build from three primary frameworks to inform this analysis. The first is the Digital Typology created by Choppin et al. (2014), in which they outlined three categories to consider when analysing DCR: students' learning experiences, curriculum use and adaptation, and assessment systems. They conceptualised the learning space in terms of learning experiences, differentiation/individualization, social/ collective features. In the second framework, Choppin and Borys (2017) look at DCR with respect to four perspectives that inform the design, development, dissemination of curriculum resources, and they explore how these perspectives lead to a foregrounding (or backgrounding) of the features described in the Choppin et al. (2014) framework. The four perspectives-private sector perspective, designer perspective, policy perspective, and user perspective-are often in tension with each other in terms of the purposes for design, the resources and capacity necessary to adopt digital programmes, and the potential to develop teacher capacity. In the third framework, Pepin et al. (2016), distinguish between three types of e-textbooks (according to their model of development and their functionality): integrative

\footnotetext{
$\overline{2}$ As with all "curriculum materials", DCR are susceptible to differing interpretations and uses by participants. While some such differences may reflect the impact of national features and culture, this is not an aspect that we investigate in this paper.
} 
e-text, evolving or 'living' e-textbook, and the interactive e-textbook.

\subsection{Theoretical framing of teacher/student interaction with DCR}

In the 2013 ZDM special issue on "Resourcing teachers' work and interactions" with curriculum materials (see Pepin et al. 2013), three theoretical perspectives on teacher interaction with curriculum materials/resources were identified: (1) design-based approaches and didactical engineering (e.g., Artigue 2011; Gravemeijer and Cobb 2006); (2) the interpretation of and participation with resources (e.g., Brown 2002; Remillard 2005); and (3) the Documentational Approach (Gueudet et al. 2012; Gueudet and Trouche 2009). In this part, rather than repeating those above-mentioned frames, we build on them and outline new ones, so that we can add to the picture in terms of teacher/student interaction with digital (and non-digital) curriculum resources. We outline three "new" theoretical frameworks.

First, in his ICME 13 paper, Ruthven (2017) asserts that digital technologies (and this may include DCR) are likely to influence instructional activity and interaction between teachers, students and resources through changes in the classroom environment and the mathematical tool system in play. He draws on recent studies that are said to illuminate features associated with the use of digital mathematical tools (e.g., Ruthven et al. 2009); and networked classroom technologies (e.g., Clark-Wilson 2010). Many of these studies lean on the framework of Instrumental Orchestration (Drijvers 2012; Trouche 2004), others on the structuring features of classroom practice (Ruthven 2014) framework in connection with technology (e.g., Bozkurt and Ruthven 2017). Both the instrumental orchestration and documentational approach (Gueudet and Trouche 2009) frameworks grew out of the instrumental approach (Rabardel 2002), and so they show significant similarities. Equally, Trgalova and Rousson (2017) have extended the instrumental approach by "networking" it with a management science approach for resource appropriation (e.g., De Vaujany 2006), to create an adapted model of resource appropriation: they distinguish between the processes of "pre-appropriation", "original appropriation", and "re-appropriation", and define the appropriated resource as "instrumentalised resource plus orchestrations".

Second, in her study of how the introduction of a classroom networking system supported development of teaching practices, Clark-Wilson (2010) concluded that its facilities enhanced formative assessment. The paper by Cusi et al. (2017) has a similar focus. In collaboration with the partners of the European Union project FASMED (Formative Assessment in Science and Mathematics Education), they developed a framework for analyzing student interaction with digital resources (e.g., Cusi et al. 2016), consisting of three main dimensions: (1) five formative assessment (FA) key strategies (as described by Wiliam and Thompson 2007); (2) three main agents (teacher, student, peers); and (3) the digital functionalities which support the three agents in developing FA assessment strategies.

Third, in an attempt to develop deeper understandings of "teacher design" (of digital or non-digital curriculum resources) and associated mathematics teacher "design capacity", the study by Pepin et al. (2017) leans on Brown's (2009) notions of "pedagogical design capacity". They develop a model for mathematics teacher design capacity when interacting with digital (and non-digital) curriculum resources. It is claimed that teacher design capacity consists of three main aspects: (1) the goal/s of the design (making the design of the DCR consistent with the aims and content of learning); (2) a set of design principles ("robust" and at the same time "flexible"); and (3) "reflection in action" type of understandings (e.g., in instruction).

Looking across the reviewed literature, we note, first, that there is a proliferation of theories in the field, which might be expected for a newly developing area of research whose "borders" have not yet been clearly delineated and "networking" of frames is common practice. Second, linked to the first point, we acknowledge that it is at times difficult to distinguish between theorisations of teacher/student interactions with technology and with DCR. Here, we have mainly referred to the theoretical frameworks supporting the studies reviewed in this article, which although often not originally intended for interaction with DCR per se, are now being used in such studies to stimulate new insights. For example, the study by de Araujo et al. (2017) leans on the framework by Remillard and Heck (2014), itself a follow-up from the work by Remillard (2005), which had been explained earlier (see Pepin et al. 2013). However, one unifying aspect across these theories appears to be that all are steeped in sociocultural theory, albeit with differing emphases according to their research goals and contexts.

\section{Issues concerning the design of DCR: mapping their functionalities for teachers and students}

In this part of the paper, we provide an overview of current design principles and developments related to DCR. We begin by discussing general categories of design features of DCR, and elaborate on those features, drawing on empirical as well as conceptual or theoretical literature. We then discuss types of DCR, to illustrate the emerging variety of efforts related to digital programmes. We relate the varied digital curriculum efforts to implications for control over and access to curriculum. We conclude this section by articulating affordances of DCR that need more intensive 
study (e.g., educative aspects of DCR; authoring capability of the materials).

\subsection{Categories of features of DCR}

In this part we articulate features of DCR, building from work in this volume as well as prior research (e.g., Choppin et al. 2014; Choppin 2016; Pepin et al. 2016) in which we articulate a range of features and types of DCR. We conceptualise three primary categories of features that are emphasised in the literature on digital materials and that are potentially transformed in digital spaces: instruction; assessment and reporting; and management.

\subsubsection{Instruction}

Proponents of DCR have noted their potential to transform the learning space to enhance interactivity and customizability (cf. Choppin et al. 2014). In our discussion, we conceptualise the learning space in terms of the presentation space, the problem space, the work space, and the navigation space, and consider how these are narrowed or expanded in DCR. The presentation space refers to the range of tools and media available to present topics to students before they engage in work on problems. The presentation space can include, for example, a video presentation that is a narrated example of a procedure or an animation to demonstrate a concept. The problem space refers to the types of problems and the range of possible solution paths or responses for the problems the students work on. The problem space can be narrow-there may only be one answer with a prescribed and simple procedure to arrive at the answer-or it can be expansive in cases where the problem has different solution paths or approaches that are accessible to students. The work space refers to the set of tools and resources available to solve a problem. We think of the work space in terms of tool availability, flexibility, and connectedness. Tool availability refers to the presence of virtual tools (equation editors, graphing utility, measuring instrument, geometry tools). Flexibility refers to the extent to which there are choices of what tools to use and how to use them. Connectedness refers to the extent to which the workspace allows for sharing with others and potentially simultaneous collective development of artifacts, such as can be done in Google docs (e.g., Pepin et al. 2016).

The navigation space refers to the potentially non-linear way that learners may progress through mathematical topics. As Choppin and Borys (2017) note, the potential complexity of digital problem spaces has the potential to "disrupt welldefined lesson structures and allocations of time (both duration and synchronicity)... interrupting the potential flow of a lesson, with implications for following a prescribed scope and sequence of mathematics" (p. xx). In addition, hyperlinked texts may alter a prescribed scope and sequence of content, changing the logic of how learners proceed from one topic to the next. As we discuss the design of existing digital programmes below, we will use these terms to characterise the learning space.

Advocates often point to the potential for the learning spaces in digital materials to be customised for the user, based on the user's abilities and performance. As will be described in more detail in the assessment part, much of the customization occurs via embedded assessment, where the programme selects content based on a student's performance on assessments. The nature of the content remains relatively the same, often low-level (Choppin et al. 2014; Yarnell et al. 2016), so the characteristics of the learning space remain much the same. Furthermore, most of the customization entails a 1-1 student-device ratio, where the student spends the instructional time interacting only with the programme.

However, scholars have discussed more nuanced means of customizing content, which is shown in the distinction between the terms individualization and customization. A goal of customization has been described in terms of achieving "a balance between characteristics of the learner and those of the learning environment, between what is challenging and productive and what is beyond the student's present capabilities" (Keefe 2007, p. 221). Individualization is seen as a learner engaging almost exclusively with a digital curriculum programme, with little interaction with others around similar academic tasks. Although such a programme may appeal to needs specific to that individual, it removes a key feature of personalisation, which requires "interactive learning environments designed to foster collaboration and reflective conversation" with other students (p. 221). Personalisation, on the other hand, involves embedding scaffolds for an individual student within a commonly shared task, in ways that modify the problem space but maintain the connectedness of the learning space, as is described in Edson (2016).

\subsubsection{Assessment and reporting}

DCR have the potential to embed assessment to provide feedback to students as well as performance data to a range of stakeholders, including students, parents, teachers, and administrators (Choppin et al. 2014). We first discuss how assessment can be embedded in the programmes and then how the data are used and reported by the programme. Assessment can be embedded in a number of ways and forms. Some programmes have multiple-choice questions or fill-in-the-blank responses that the programme automatically records and evaluates. These operate in much the same way as traditional assessments, providing percentage of correctly completed items, most of which are procedural or factual (Choppin et al. 2014). In some programmes, students must pass an assessment before they are allowed to proceed to a 
subsequent content. If they do not pass the assessment, they are often provided additional examples or other remedial content before re-taking an assessment.

There are more subtle and sophisticated forms of assessment in a number of digital programmes. In Dreambox, for example, students are assessed based on their actions with manipulatives. The programme analyses the students' actions to determine which strategy from its typology they best match, and then reports that strategy to the student or parent at the end of a sequence of activities (Choppin et al. 2014). Video games with educational aims-though not DCR by our definition-can include stealth assessment, where the programme collects analytics on users' actions, such as where they position a fulcrum within a balancing problem in physics, with the goal of tying the users' actions to mastery of some learning outcome (Shute and Ventura 2013). Intelligent tutoring systems provide feedback and scaffolds related to a narrow range of potential strategies (e.g., Aleven et al. 2016). These tutoring systems are typically based on a mastery learning model of content divided into discrete bits, and guide students through narrowlydefined topic sequences.

Digital programmes do a variety of things with the assessment data that they record. As noted above, what are termed "adaptive" programmes regulate students' progression from one topic to the next, choosing the material provided accordingly. Typically such programmes rely on student performance on multiple-choice or fill-in-the-blank items to decide whether to move on to the next topic or to continue with the current one. As reported in more detail elsewhere in this special issue (Choppin and Borys 2017), a number of studies funded by the Gates Foundation and other foundations have shown that the use of adaptive courseware gave rise to modest learning gains, but that these gains were usually associated with narrowly focussed and relatively simple content; furthermore, the use of these programmes slowed the pace at which content was covered and completed and did not address deep learning when needed (Means et al. 2014; Yarnell et al. 2016).

In terms of data reporting, there has been considerable discussion of data dashboards that display summaries of individual or whole class performance on individual tasks and complete tests, with reports showing progress on particular standards (Choppin et al. 2014; Choppin 2016). These displays show summative data on the percent of skillbased items successfully completed, and can relate them to specific learning targets and can report by class or group.

\subsubsection{Management}

DCR are often coupled with learning management systems (LMS) that integrate curriculum with management features, such as assessment reporting, attendance recording, and other administrative features. Digital programmes housed within LMSs are typically developed by large-scale publishers (Burch and Good 2014; Choppin et al. 2014), who want to offer comprehensive systems to schools that embed a full range of curriculum content.

\subsection{Types of DCR}

In this part of the paper, we categorise the development of DCR to illustrate the variety of players, platforms, and design and development philosophies. We build from existing work that describes types of digital textbooks being developed, and expand that work to include efforts that do not easily fit into the category of textbooks.

\subsubsection{Types of textbooks}

Pepin et al. (2016) distinguish between three types of e-textbooks. The integrative e-textbook "refers to an 'add-on' type model where the digital version of a (traditional) textbook is connected to other learning objects" (p. 640). This model includes e-textbooks that are simply digitised versions of existing textbooks, with additional links and digital tools added in the student text. In addition, the digitised texts may allow teachers to add additional links and resources of their own choice or design. Examples include digits (http:// www.pearsonschool.com/index.cfm?locator=PSZwZ5) and CINCH (http://www.mhcdi.com/cm_about.html), which took previously developed materials, digitised them, and added distinctive digital features, such as dynamic tools and interactive media (Choppin 2016). Primarily, the impact of the digitised versions of these materials was in the presentation space, where the developers added media to introduce or explain topics (Choppin and Borys 2016). These developers also embedded their curriculum programmes in LMSs, which are prominent in the way these programmes are publicised.

Pepin et al. (2016) describe an evolving or 'living' e-textbook as an "accumulative/developing type model where a core community (e.g., of teachers, IT specialists) has authored a digital textbook, which is permanently developing due to the input of other practicing members/teachers" (p. 640). The Sésamath programme in France is an example of such a programme, and the programme is constantly being revised based on input from teachers, who, in consultation with the core design team, revisit the resources. The characterization of e-textbook as evolving or living refers mainly to the model of development (i.e. through input from practicing teachers).

The third model described by Pepin et al. (2016) is the interactive e-textbook, which refers to a model where the textbook is wholly "based upon a set of learning objects: tasks and interactives (diagrams and tools) that can be 
linked and combined" (p. 640). These programmes involve the ubiquitous presence of tools for students to use as they work on problems. These tools may be tailored to particular topics, as is the case with VisualMath (Yerushalmy 2016), or constant across topics, as is the case with a textbook developed in Korean (Lew 2016). These 'toolkit' approaches provide access to a suite of tools that learners strategically select as they engage with complex problems. These tools include dynamically linked representational tools (equation editor, graphing tool, table) that can be used flexibly to solve problems. For these programmes, the primary impact of their digital design was primarily on transforming the work space and, to a lesser degree, the problem space. In addition, the tool-rich work space may lead to incidental discussions and unanticipated approaches, potentially affecting the navigation space as well.

\subsubsection{Other kinds of efforts that elude categorization as a textbook}

In addition to the three types of digital textbooks described above, there are other digital programmes that do not easily fit the category of a textbook but that involve comprehensive efforts to cover a scope and sequence of content for one or more courses or a set of standards.

The first type of DCR involves curation, where a third party evaluates online materials and organises them into a curriculum sequence. Examples of curation include commercial entities, such as Amazon, where an entity contracts with teachers or designers to select and organise the content, which is then embedded into a website sponsored by the entity. Alternatively, curation can involve researchers who select and organise activities from the web and then connect those activities to a research-based learning trajectory (Confrey 2016; Confrey et al. 2017). The curated curriculum sequence is augmented by diagnostic assessments that can be used to help teachers track student learning in lieu of typical textbook-affiliated assessments. Similar to the characterization of e-textbooks, the primary impact of the digital nature of the resources primarily relates to the development model as opposed to consistent changes in the learning space.

There are similar types of efforts that generate repositories of lessons that are organised into a curriculum sequence that is often associated with a national curriculum. One model that involves the creation of a repository of lessons involves small author teams operating under a uniform design philosophy, such as with the cases of Khan Academy (https://www.khanacademy.org/), sofatutor (https:// us.sofatutor.com), and Hélice (Chesné et al. 2009). These efforts often focus heavily on the presentation space, with collections of videos or animations for each topic that demonstrate a topic or explain a procedure. These efforts also include a problem space that typically involves problems found in hard-copy textbooks, and there may be assessments that resemble traditional assessments but are recorded by the programme.

In other cases, larger, more disparate teams of teachers or designers are contracted by an entity to develop lessons that have similar production features (e.g., teachers explaining content using a particular format or programme). These lessons are then integrated into a website that hosts the lessons, explains the development philosophy, and then potentially incorporates assessment or management features to make it a fully serviceable curriculum programme. Examples include Illustrative Math (https://www.illustrativemathematics.org/) and Discovery textbook (http://www. discoveryeducation.com//what-we-offer/techbook-digitaltextbooks/?campaign=nav_digital_textbooks). Similar but less glossy efforts include LearnZillion and Yourteacher, whose lessons are developed by teams of teachers organised by a single entity, following a uniform production format (Choppin 2016). Unlike Sesamath, there is less of an emphasis on collaborating on or iterating the design of these resources (Pepin et al. 2016). In these programmes, the primary digital focus is on the presentation space.

\subsection{Discussion}

The overview of the current state of design principles evident in digital materials shows how they may transform the learning space relative to hard-copy texts and signals emerging trends in terms of development. In this part we summarise the findings related to the design of digital materials and then suggest some implications for curriculum more broadly. The potential of digital materials to transform the learning space is most amply manifest in the presentation space. Many of the programmes mentioned above use videos or animations to introduce topics, and many of the programmes publicise the engaging nature of these presentations as a means to get students hooked into working on the subsequent problems.

The problem space in many cases mirrors what is in hard-copy programmes, with sets of problems that are well bounded in terms of the expected solution approaches. Most of the adaptive programmes focus on procedural mastery in the design of the problem space. Thus, for the typical DCR, the relation between the presentation and problem spaces remains the same as in the typical paper-based curriculum programme, in that that the presentation space provides exposition, in which worked examples play a central place, with the problem space then providing students with examples for practice. The exceptions are programmes that require students to manipulate objects to demonstrate performance, such as in Dreambox and Algebra in Action (Choppin et al. 2014). Intelligent tutoring systems attempt 
to create a more open problem space (Aleven et al. 2016), but are often constrained by the necessity of anticipating a small range of solution strategies around which to create scaffolds or feedback.

The transformation of digital work spaces is still relatively rudimentary, with the exception of the interactive e-textbooks, such as those described by Lew (2016), Pepin et al. (2016), and Yerushalmy (2016). In these textbooks, tools are ubiquitous across the materials; furthermore, these tools are quite flexible in that they can be used across multiple topics and can be employed in a variety of ways and in any order. There is less emphasis on the connectedness of the work space, though Edson (2016) shows how work spaces can include collectively generated and shared student solution-related artifacts.

The platforms in which content is embedded vary across programmes. Though all of the programmes mentioned above are web-based, the websites have different functions. In the cases where websites are largely repositories of lessons, the sites typically have a few primary pages that are used to point to content, with some explanation of the entity that owns or operates the site and possibly some rudimentary supplementary features. In other cases, the sites incorporate LMS features including extensive assessment tools, reporting features, and supplementary teacher resources and administrative tools.

The entities involved in the design and development of DCR vary considerably. In some cases, large corporations or philanthropies fund the programmes, such as the case of large commercial publishers and philanthropies like the Gates Foundation. As described in more detail in this issue (Choppin and Borys 2017), these entities typically emphasise adaptive programmes based on the mastery approach. Furthermore, these programmes minimise the role of the teacher, often relegating teachers to administrating rather than instructing. Other non-profit or philanthropic efforts take an entrepreneurial stance towards the development of materials, gathering teams of teachers and designers who produce content that is then offered to others to use (e.g., Illustrative Math; LearnZillion; YourTeacher). More collaborative endeavours include Sésamath, where teams of teachers and designers collectively design materials, but which are then revised based on feedback by the network of users (Pepin et al. 2016). Another set of developers are those who explicitly build from research on learning and teaching to design programmes; typically these programmes are most transformative with respect to the problem and work spaces (e.g., Confrey 2016).

\subsection{Implications}

The emergence of a wide array of actors and types of programmes, many freely available on the web, has implications in terms of how curriculum is framed and enacted. First, the coherence of curriculum programmes may suffer as authorship is distributed across authors who do not communicate directly with each other, as is the case in a number of the repository models. While authors may create lessons that are situated on the same platform using similar production tools, the lessons are unlikely to be as connected to each other in ways that smaller author teams are able to accomplish. For example, Gueudet et al. (2013) analysed two different textbooks, one "traditional" textbook accompanied by digital resources, designed by researchers and teacher educators (Hélice); and the other a "true" digital interactive textbook, designed by teachers (Sésamath). Each group privileged different design features such as multiple solution strategies versus expert solution or ease of adaptability of lessons. The Sésamath programme, designed by a collective of teachers, lacked coherence in that the distributed authorship made the activities atomised, without an underlying philosophy or structure guiding the development of the book (except the one coming from the French National curriculum), though there is no research that has explicitly demonstrated an impact from the coherence (or lack of coherence) of curriculum materials. However, its wiki-like nature also made its development ongoing and dynamic, and useful to teachers. The other text, Hélice (Chesnè et al. 2009) was developed by a small team of four authors, three teacher educators and a researcher, and had a more coherent philosophy: Hélice was organised around a developmental cycle where students revisit content over time in a spiral. The difference in design processes between the two texts is significant because for a spiral organization to occur designers must be aware of and in communication with each other about content and activities. This communication and awareness is difficult when design decisions are diffuse, such as with the Sésamath team.

Second, with the profusion of DCR that are accessible across the globe, there is an increased likelihood that educators will select curriculum materials that do not derive from regional or national curriculum documents. This may loosen the link between curriculum policy and practice, with at least two potential outcomes. The first outcome is that large commercial publishers may have ever larger influence given their ability to publicise materials and tailor marketing of them to different contexts (see Choppin and Borys 2017, for a more extended discussion on this point). An alternative outcome may be a greater diffusion with respect to curriculum development, with a wide range of programmes developed using a variety of models and actors as described above, loosening the grip of national policy makers and commercial textbooks publishers (Chazan and Yerushalmy 2014). Sésamath, developed by a collective of teachers and designers and iteratively refined by a wide network of users, represents a model that diverges from traditional textbook development that takes advantages of the affordances in digital spaces. 
This speaks to the revisability or authoring potential found in some e-textbooks, where users can revise and adapt the materials to create their own courses and sequences (Pepin et al. 2016).

\subsection{Areas that need increased emphasis}

In our brief overview of the development in and literature on the design of DCR, we noted a lack of focus on the educative nature of DCR. That is, despite strong calls to make the rationale and design of curriculum more apparent to users so that they use them more productively (Davis and Krajcik 2005), there are questions about how this might be accomplished in digital materials (e.g., Remillard 2016). A second area in need of greater emphasis is design in the context of digital tools. Research focusses on whether the tools are effective and on how teachers use them, but design is rarely taken up explicitly, though this topic has received attention recently. The third area that needs more research is on the authoring capabilities of digital textbooks, an area briefly touched on by Pepin et al. (2016); and which kinds of connections are made in (and from) e-textbooks (e.g., Gueudet et al. 2016) in order to help to evaluate their potential interactivity.

\section{Issues concerning the "use" of DCR (with or without traditional materials) in and out of school}

In this section we identify and discuss issues associated with (4.1) teachers' and (4.2) students' interactions with DCR.

\subsection{Teacher interaction with and use of DCR in/for their mathematics instruction}

Most mathematics teachers (at least in Western countries) now have access (via the internet) to a profusion of openly/ freely available educational resources (e.g., Open Educational Resources), which include digital lesson plans; model-based simulations; video presentations; instructional software, to name but a few types. However, teachers often find it difficult to analyse and choose from the profusion of materials available to fit their educational goals and classroom contexts (e.g., Larkin and Milford 2017). The issues of quality and coherence are as relevant for teacher design of, and interaction with, DCR in their everyday work (e.g., of lesson preparation; or in class), as they are for professional designers. In this part we distinguish between teacher interactions with DCR individually, e.g., for individual lesson preparation (often done at home) (T-M); in collectives either with colleagues (e.g., in teacher professional development) (T-T-M), or when they work with students in class $(\mathrm{T}-\mathrm{S}-\mathrm{M})$.

Whilst there is a wealth of studies investigating mathematics teachers' work with, and use of, curriculum materials and resources in general (e.g., Gueudet et al. 2012; Pepin et al. 2013; Remillard et al. 2009), there is less research with a specific focus on individual teachers' work with DCR, a little more on teachers working in collectives. At the same time many of the benefits reported from studies of the development and use of digital resources are identical to those reported by earlier studies with non-digital resources. For example, in a recent study (see below, e.g., Essonier et al. 2016) the "MC Squared" team investigated the role of context in "social creativity" for the collaborative design of digital educational resources (e.g., c-books) with a new technology enabling the meshing of text with dynamic digital widgets. Their results suggest that (supported by an appropriate technology) the collaborative design in collectives of individual designers carrying a different background and set of personal and professional concerns, can bring about new, alternative and promising ideas, solutions and implementations (from the designers) thus leading to a richer and improved design (both as a process and a product).

In terms of mathematics teachers' (and students') working with e-textbooks, there has been a sizeable amount of research by the Israeli team of Yerushalmy and colleagues (e.g., Naftaliev 2016; Naftaliev and Yerushalmy 2013), and by the French teams investigating the Sésamath textbooks' design and use (e.g., Gueudet et al. 2016). Naftaliev (2016) examines the professional learning of prospective teachers, when developing lesson plans and scenarios of student-textbook-teacher interaction (T-M). She focussed on "interactive diagrams" (i.e. interactive text), a key component of an innovative e-textbook. Her findings showed that when analyzing scenarios of classroom situations, the prospective teachers got involved with students' thinking with the interactive diagrams (e.g., they discussed different ways in which students used diagrams for solving processes), so that they could identify and understand students' (sometimes new and creative) paths for the construction of mathematical meaning with the diagrams. This study shows how new (components of complex) digital materials can provide opportunities for teachers to shift their pedagogical practices towards (understanding and) creating new ways of meaning making in mathematics.

The French e-textbook Sésamath has been quite unique, it seems. The Sésamath association has created a platform where teachers contribute to the re-design of a now established and commonly used e-textbook, developed and produced solely by practicing mathematics teachers. The collective design (by a selected Sésamath teacher team) of the grade 10 functions chapter of Sésamath has been documented in the study of Gueudet, Pepin, Sabra, and Trouche 
(2016) (T-T-M): the findings show different design processes, more particularly the factors shaping the choices of content and structure, and the consequences of this design for the community. Inspired by new possibilities offered by technology, the Sésamath teacher team originally planned to build a "toolkit", which was intended to help user teachers to build multiple different pathways through the topic area (of "functions"). Firstly, they found that "not all pathways (through the topic area of functions) are relevant", according to their shared beliefs, but that particular "kernels" should be taught and particular progressions were identified. Secondly, in negotiations with the information technology specialists it appeared that, whilst there were "disruptions" and advances due to technological innovations (i.e. interactive exercises), the initial ideas proved unattainable, and the final design showed more continuity (of previous designs) than expected. The Sésamath teachers designing the e-textbook had their own convictions about how "functions" should be learnt, which shaped the learning trajectory presented in the book. Whilst several pathways for learning "functions" were in principle possible, to offer them in the same e-textbook proved to be too difficult. Although technology could help them to introduce selected structures (e.g., of exercises) in more flexible ways, the ways these were put together in the learning trajectory/ies were nevertheless shaped by the teachers' didactical understandings of learning "functions".

In another study (Pepin et al. 2017) evidence is provided of how individual teachers (e.g., Vera, French teacher) can work with the Sésamath e-textbook (T-M): (1) using Sésamath tools and content for lesson sequence design/preparation; (2) using Sésamath digital tools to talk directly to students and provide them with individualised learning exercises/homework; (3) keeping a written record of what students should write into their "lesson books"; (4) writing in to the Sésamath association to vary/change an explanation or exercise, to name but a few of the affordances. In the same article, Vera's use of Sésamath is compared to that of another teacher (e.g., Cora, Norwegian teacher) working with "designer-made" digital materials (produced by a European Union supported team) (T-M, T-T-M). Both teachers adapted the curriculum materials to their needs; indeed they "picked and chose" appropriate materials, and were inspired by some of the innovative pedagogical features afforded by the digital nature of the materials. For example, Vera used the digital environment of Sésamath to develop differentiated exercises (e.g., in terms degrees of help for solving the same exercise) for her students, and in class she gave them the choice which one/s to attempt. Cora used the DCR (modules of the digital professional development programme) to develop questioning for her students. This suggests that these mathematics teachers benefitted from work with quality DCR, in particular when they worked with colleagues and teacher educators in professional development sessions.
There is evidence that these teachers enhanced their design capacity through the work with the digital resources (Pepin et al. 2017), and in particular the "flexibility" (in addition to the "quality") of the resources was mentioned as a deciding factor.

In another European Union funded project ("MC Squared", e.g., Kynigos and Kolovou 2016) teachers worked collaboratively as designers of digital educational resources (so-called "c-books"; "c" for creative, extending e-book technologies to include diverse dynamic widgets and an authorable data analytics engine) ${ }^{3}$ aiming to foster students' creative mathematical thinking. The findings suggest that during the design process of a c-book unit of "Climate Change" the socio-technical environment allowed the communication and coordination of diverse perspectives and the creation of narrative with dynamic artifact-widgets designed to induce mathematical creativity. It has been claimed that the interactions allowed by the socio-technical environment enhanced teachers' design capacity, and the socio-technical environments could act as a driving force for classroom innovations. In another study within the frame of the same project (i.e. Essonnier et al. 2016) the main forces shaping the decision-making in a "c-book" design process were investigated. It is claimed that two main forces shaped the decision making in the design process: the tools (e.g., those connected to the c-book affordances); and culture (cultural contexts of participating design teams). Furthermore, in an effort to develop deeper understandings of the interplay between teacher professional knowledge and his/her interaction/s with DCR, Trgalova and Rousson (2017) investigate the processes of appropriation of a digital game (to teach enumeration skills) by teachers. Results show that the appropriation of a digital resource (by the teacher) depended on its flexibility, that is, on its affordances for more or less flexible processes to occur. At the same time it appeared that "a solid mathematical and didactical knowledge" (in terms of the mathematical content implied in the digital resource) was the main factor for success in terms of the teacher appropriation process/es.

In mathematics education there are reports of a steady increase in teachers flipping their instruction, i.e. assigning instructional videos as multimedia for their students to watch at home, and setting problems and exercises in class. In a study by Araujo and Otten (2017) a teacher created her own instructional videos and multimedia resources as curriculum materials, and replacements for printed textbooks; it is claimed that here the teacher became a curriculum developer. The research team investigated the role of the teacher in the creation of the DCR (T-M), and the interactions of the teacher and her students with those materials in

\footnotetext{
$3 \mathrm{http}: / / \mathrm{mc} 2 \mathrm{~d} m e . a p p s p o t . c o m / \mathrm{mcs} /$.
} 
class. Results suggest that the teacher designed the videos according to the textbook, in fact the videos were "scripted" by the book: the videos showed her teaching, as she would normally do, relying on the textbook and highlighting problem areas and misconceptions, which reflected her beliefs and experiences concerning mathematics learning. Thus, the videos aligned to a large extent with the conventional textbook, and the teacher used the lecture videos for purposes similar to printed textbooks (e.g., presenting worked examples, definitions). However, the videos were "self-produced" by the teacher, which allowed for some personalization and accommodation. Similarly, students drew on these materials in the same ways as they did on printed textbooks. In other words, the teaching and learning practices did not change, and the teacher maintained her role as instructor. Indeed, for the students the videos took over the role of the textbook (and they did not often refer to it), which provided room for the teacher to take over the "authority" of the textbook, as mediator, in the videos. Hence, the videos were "a pivotal source of content" and examples were used in and out of the classroom, hence became a kind of curriculum material (Araujo and Otten 2017).

A similar picture is also painted by the study of Murphy et al. (2014) on curriculum materials by the Khan Academy, and as reported on by Ruthven (2017). This study found that teachers preferred to introduce new topic areas themselves, through teacher-led classroom instruction, rather than using the Khan Academy videos for this purpose (T-M). However, they did use the Khan Academy problem sets extensively, for student practice, and both teachers and students in the study appreciated the student-system interaction associated with these problems sets: the system provided immediate feedback on the answers entered. Hence, as in the Araujo and Otten study (2017), teachers (and students) appropriated and used the DCR for their own ways of teaching (and learning). Interestingly, the Khan Academy designers responded to this by modifying the system so to be "easier appropriable" by the teachers (and students), in particular core features such as the user interface of the video resources, for example. At the same time, however, the designers also brought in new changes towards their intended vision: in this case a personalised approach to learning. Hence, the Murphy et al. study is a suitable example for showing a "two-way process of adaptation" (Ruthven 2017), where the "user" (teacher, student) adapts the intentionally designed materials for their own goals and purposes, whilst at the same time the designer/s adapt to the users' preferences (whilst bringing in some of their goals too) based on the Murphy et al. study results. In the case of Sésamath there was also an adaptation process: the teacher used the Sésamath curriculum materials for their purpose, and wrote in to the association when proposing to change anything in the books-a "negotiated adaptation", between the teacher/s and the Sésamath association.
Moreover, well-designed "educative" curriculum materials (e.g., Davis and Krajcik 2005) are often used in/for teacher learning and professional development $(\mathrm{T}-\mathrm{M}$; $\mathrm{T}-\mathrm{T}-\mathrm{M})$. These materials include educative components that may help teachers for effective lesson preparations and instruction, or to adapt activities and tasks for differentiated and individualised learning. In a study by Bates (2017) it is claimed that digital tools can support teachers in various ways and transform the kinds of educative information provided to teachers (T-M). Bates describes two promising approaches that take advantage of digital affordances to enhance teachers' educative experiences, amongst them the feedback approach. This approach has been used in the design and development of CurriculumKit, a web-based app that allows teachers to plan lessons in the University of Chicago School Mathematics Project (UCSMP) Algebra curriculum (Brown et al. 2007), make changes to lessons and get immediate feedback on the implementation of those plans and changes for student learning. The digitization is expected to allow teachers to fully adapt and interact with the curriculum and to "provide real-time feedback on those adaptations and interactions". She predicts that DCR developers will find more suitable and creative ways to promote teacher learning, in addition to more customised ways designed to support teachers at different levels of their development stages (e.g., novice and/or experienced teachers). Indeed, she foresees that in the future curriculum designers will no longer "write lessons", but rather use their expertise to work with teachers as they become the designers of their own materials, and in that sense supporting them to develop design capacity.

To summarise, it appears that there are at least three features that make it beneficial for teachers to work with DCR: (1) their flexibility in terms of adaptation and redesign, for personal lesson preparation as well as collective design work with colleagues, at a distance or working together in professional development sessions; (2) the possibilities for personalization and differentiation, so as to attend to students' individual needs, for example, in providing particular tasks/activities or individual feedback on tasks; and (3) the many assessment features that allow "easy" access to different aspects of pupil learning.

\subsection{Students use of DCR in/for their learning}

In this part we distinguish between (a) student individual interactions with DCR (e.g., working on their own at home or in class) (S-M), and (b) when they work with their peers in class $(\mathrm{S}-\mathrm{S}-\mathrm{M})$. 


\subsubsection{Student interaction with e-textbooks}

Just as there is already a scarcity of literature concerning students' work with conventional mathematics textbooks (e.g., Rezat 2013), it appears that there is a dearth of studies attending to students' use of e-textbooks. The work of Yerushalmy and her team (e.g., Naftaliev and Yerushalmy 2013; Yerushalmy 2006: S-S-M) and Rezat (e.g., Rezat 2017: S-M) are amongst the exceptions. Based on studies of students' utilization schemes of traditional textbooks (e.g., Rezat 2013), in this case similarity of visual appearance, Naftaliev and Yerushalmy (2013) investigated students' problem solving with e-textbooks, more particularly student learning with interactive visuals/diagrams when problem-solving. Knowing that diagrams can help students to structure their ideas by making them meaningfully visible and concrete and to engage and focus on sense-making processes (Murata 2008), they studied structures of design and affordances of interactive diagrams and analysed students' problem-solving experiences with e-textbooks. One of the unexpected results was the "unusually extensive mental work, encompassing an entire cycle of logical argumentations (raising assumptions, deriving conclusions through conjectures and refutations) which eventually led to the solution" (Pepin et al. 2016, p. 646), Their evidence (Naftaleiv and Yerushalmy 2013) suggests that interactive tasks offer engaging reading by providing readers with explicit options for manipulating given examples and diagrams in particular. However, they also caution that important fine-tuning should be considered for the design of e-textbooks, to include the following:

1. well-planned interactive examples that present the necessary repertoire of examples that would provide cognitive support (rather than cognitive load);

2. partial control and partial links between representations that help capturing interesting "views".

As another example, Rezat (2017) studied students' utilization of feedback by an interactive e-textbook (S-M). Based on the assumption that one of the affordances of digital learning tools is that they can provide different kinds of feedback to students, he qualitatively studied two-third-grade students' responses to feedback in an interactive e-textbook environment. Results indicated that students used the feedback differently, which in turn has consequences for the effectiveness of feedback. The study by Rezat provides a helpful link to the next part, as many DCR are designed to provide support for students learning mathematics through formative assessment and feedback.

\subsubsection{Student interaction with and through DCR}

In an effort to enhance students' mathematical learning through formative assessment/assessment for learning by providing DCR in a connected classroom technology environment (see Cusi et al. 2017: S-S-M), the Cusi team analyses the use of digital worksheets with a particular framework that includes different functionalities for the technology, formative assessment strategies, and actors involved. The materials used were three kinds of digital worksheets ("problem worksheets"; "helping worksheets"; "poll worksheets") that could be sent (from teacher to student and vice versa) and displayed (on students' tablets, or teacher's computer/ Interactive Whiteboard); they were designed to foster students' development of ongoing reflections on their learning processes and making their thinking visible. Results showed typical patterns of evolving formative assessment strategies when working with the worksheets in the lessons.

Turning to mainly summative assessment/assessment of learning, the team of Yerushalmy investigated the design of e-tasks for assessment purposes, focussing on design principles of e-tasks that encourage exploration (based on paperand-pencil tasks). Students worked individually (S-M) without external help (e.g., the teacher, and after having studied the content in class) on the tasks (Haddif 2017). Results showed that in the redesigned e-tasks (from paper-and pencil tasks) certain criteria should guide the technological affordances: the technology should allow for self-reflection; promote learning during assessment, and guide the students to focus on important details of the tasks without unnecessary distractions. Moreover, based on the assumption that the same technology can change as well as assess learning, Yerushalmy et al. (2017) examine whether and how automatic assessment can inform the learning of advanced mathematical concepts (in calculus), including real-time analysis of answer submissions and free hand sketches. Results point to the suggestion that e-assessment should be "suggestive" rather than deterministic about students' work, so to leave room for amendments and misinterpretations.

In a comprehensive study of diagnostic assessment designed around learning trajectories, Confrey and her team (e.g., Confrey and Maloney 2015; Confrey et al. 2014, 2017) addressed issues associated with the development of coherent learning trajectories across the curriculum using DCR (e.g., OER) as part of a digital learning system (DLS). The assumption is that when teachers rely on OERs, the coherence of the resulting learning experience is often undermined, with coherence being a hypothesised criterion of curricular quality (e.g., Nieveen 2009). The DLS was designed with the aim of increasing curricular coherence by (1) providing guidance using a learning map; (2) providing data on student learning using diagnostic assessments, and (3) enhancing the usefulness of OERs (Confrey et al. 
2017); all that in order to support students to move from "naïve" to "sophisticated" understandings of mathematical ideas. Looking across the DLS it is clear that it shares many characteristics with an e-textbook, but it is also clearly different in the sense that it provides a "learning system", with selected components that are meant to support learning with a set of targets, instructional materials, and perhaps most importantly, with real-time data to act as feedback to students (and teachers) about learning (S-M). Also working with low achievers, Dvir and Tabach (2017) investigated how students could come to a more sophisticated understanding of concepts in calculus when working with a digital dynamic environment. Results point to the ease-of-use of the electronic spreadsheet and its ability to generate and repeat the built-in formulas as one of the main facilitators for the construction of ideas and knowledge (about the conditions for equality and inequality relations, for example). The team suggests that the ease-of-use might have encouraged the students to extend their experimentations and realisations beyond the scope of specific tasks and to further explore ideas.

In contrast to Confrey's research, Edson (2014, 2016, 2017) investigated how students (themselves-S-M) navigated through sequences of connected problems (designed to leverage the affordances of a digital learning environment), which were organised around open-ended problems linked to learner-controlled scaffolding. The findings suggested that when students can control the level of access and challenge (when problem solving in a digital medium), new possibilities (e.g., with learner-controlled scaffolding in a digital learning environment the thinking and non-linear growth can be documented, as students traverse along different pathways, hence alert teachers to differences between intended and observed problem-solving pathways) arise for sequencing the problems through which students can progress.

To summarise, we note that the interactive features of DCR appear to become most useful with formative assessment practices, which help students (as well as teachers) to "feed forward", that is to drive the next learning (instructional) steps (both for S-M and S-S-M). At the same time it appears that the general adaptivity of such DCR, in particular with respect to personalised (diagnostic) assessment, is one of the biggest advantages, as Ruthven (2017) points out:

"Indeed, it seems that many current digital curriculum programmes aspire to (individualize instruction and) 'personalise' learning. Particular strengths of such programmes are their use of adaptive assessment to tailor the content presented by the system to the response history of the student..." (p. 10).

This adaptivity appears also crucial for finding new pathways and sequencing of problems by students, and in terms of assessment for leaving room for misunderstandings and amendments.

\subsection{Discussion}

This part is structured according the criteria of relevance; consistency; practicality; and effectiveness (Nieveen 2009). Considering relevance, it is clear that the digital resource has to "solve a problem", it has to be useful, for the teacher (or student) to design and use it; it has to serve a (sometimes pressing) need. For example, de Araujo et al. (2017) studied a mathematics teacher's design and use of video as curriculum material. They found out that, contrary to the "usual" use of video for flipping the classroom, this teacher actually scripted the video according to the textbook, in order to "free" herself and her students from textbook use. On the video she could teach her lessons "according to the book" and at the same time add her own insertions about misconceptions and problem areas (as she would do in class previously). This "solved her problem" of teaching (as she would have done in class) and attending to her students at the same time: for her all ingredients of good teaching (as perceived by her) came together using this tool as DCR. In the study by Pepin et al. (2017) both Vera and Cora chose and used the digital materials to address a particular need: Vera wanted to improve her differentiation in class; and Cora her questioning.

Turning to consistency, it appears that there are different levels of consistency that can be addressed. For example, in the study by Confrey et al. (2017) consistency of the designed materials is related to coherence: with the DLS mathematics teachers were helped to find coherent learning trajectories through the DCR (e.g., OERs), being provided with learning maps and a diagnostic assessment system. It was claimed that these tools are necessary to guide teachers, rather than simply providing them with a "box of tools". Coherence and consistency was also part of teachers' design capacity (according to Pepin et al. 2017), so that teachers are aware of the different levels of consistency, and subsequently can fit their designed materials into their developed learning trajectories (consistency across the topic area), into the curriculum across the years (of mathematics learning) and into the "horizon curriculum" (e.g., from school to university mathematics), and into the curriculum as a whole (i.e. integration with other subject areas), for example.

In terms of practicality, we distinguish between (a) instrumentality (i.e. must be instrumentally feasible for the teacher); (b) congruence (congruent with teachers'/students' perception of own situation, how does it fit into the teaching and learning situation, etc.); and (c) cost (return versus investment of the teacher/student) (Doyle and Ponder 1977). In Yerushalmy et al.'s (2017) study it became clear that these three aspects need to be balanced for (teachers and) students to gain the desired outcomes: the aim was to provide students with especially designed e-tasks (interactive) and suitable tools that allowed for students to express 
their mathematical ideas, and at the same time minimise the need for interpretation of students' meaning making by the teacher, as feedback was provided automatically by the system. The balance here was between suitable tasks (to motivate enriched example space), a congruence aspect; the instrumentality of the system to analyse dimensions of individual variations with groups of students, and personal submissions, as an automated system; and the "cost" in terms of the efforts of the teachers versus the learning outcomes of the students.

Lastly, effectiveness relates to student learning outcomes, that is, whether the design obtained the desired effect in terms of enhanced learning. In the study by Dvir and Tabach (2017) the team investigated traced students' knowledge construction processes whilst solving extrema problems in an e-resource (GeoGebra) environment. Their findings allowed them to identify the affordances and constraints/drawbacks of the e-resources for student learning at micro level. Moreover, the students could not only solve the extrema problems, but also explain their reasoning in ways that reflected their use of the e-resource.

\section{Conclusions}

The findings of our review reflect the challenges, which have emerged - both in professional practice and educational theory - to many classic demarcations and models.

First, although we were able to identify some contrasting tendencies between research on instructional technology as against that on digital resources-broadly, a greater concern of the latter with use in mainstream professional practice, as well as some differential privileging of theoretical frameswe also found significant convergence-most notably in the increasing use of digital platforms for curriculum materials and the integration of forms of instructional technology into these platforms. Equally, we found important commonalities of basic theoretical orientation-particularly with respect to sociocultural theory despite the sometimes differing emphases and extensions in the two bodies of research. Clearly, there is scope for further cross-over and convergence-both practical and theoretical-between what have traditionally been seen as distinct fields.

Second, while some of the work that we have reviewed reflects a continuing demarcation between design and use, designer and user-notably in the commercial development of full-blown schemes of curriculum materials-other examples not just reflect, but actively champion, the notion that design continues in use, assisted by the greater provisionality of digital resources and the way in which digital communication affords exchange, feedback and adaptation within professional communities. Such examples include the evolving or 'living' e-textbook-under continuing collaborative redesign in response to input from teacher users-and the open digital pedagogical configuration, providing a framework of learning trajectories and diagnostic assessments, with individual nodes provisionally populated by the developers' curated selection of online resources. Given the research on the ways in which traditional textbooks position mathematics and frame the relationship between teachers, students and mathematics (Herbel-Eisenmann 2009), it will be interesting to explore how DCR—which might be seen as more mutable, provisional-might provoke shifts in the perceived authority either of the teacher or the mathematics.

Third, many of the developments that we have reviewed display a weakening of traditional demarcations between pedagogy and assessment and between summative and formative techniques of assessment. Indeed, developments such as the embedding of stealth assessment in the design of individualised adaptive learning systems in which automated processes of assessment underpin tailoring of experience and monitoring of performance suggest that we may need an expanded map of assessment form and function which acknowledges new dimensions of covert to overt, adaptive to informative, episodic to continuous. In other examples, digital resources have been found to provide a medium that enhances possibilities of formative assessment due to their particular potential to provide rapid feedback and facilitate sharing of ideas.

Finally, our review has identified an expanded space of interaction associated with the shift from conventional static non-reactive print-based resources to dynamic responsive digital resources, and to more active mediation by the latter: a change which, it has been suggested, warrants a corresponding expansion of the analytic heuristic of the didactical triangle (of subject matter, teacher and student) by adding a fourth (technology/medium) vertex to create a didactical tetrahedron (Ruthven 2012). Indeed, such a development may become more pressing: we noted how, at present, change in commercial curriculum programmes was primarily in the presentation space, with some modifications in the problem space, but no significant change in the work space or the navigation space. As change becomes more far-reaching, we would expect the analytic importance of acknowledging mediation to become much more significant. For example, a hypertext-based navigation space downplaying a rigid sequencing of curriculum topics has the potential to support very different notions of personalised learning to those expressed in the strongly linear-hierarchical design of current curriculum programmes. Alternatively, a different type of workspace might change the one-to-one interaction of student to textbook that has been predominant with traditional textbooks. The multiple input potential of multi-touch devices, for example, accompanied with carefully designed tasks, may reconfigure work spaces to enable many-to-one interactions. 
Hence, we claim that DCR offer opportunities for change: of understandings concerning the design and use of curriculum materials; of their quality; and of the processes related to teacher/student interaction with those digital materialsthey provide indeed the foundations for change.

Open Access This article is distributed under the terms of the Creative Commons Attribution 4.0 International License (http://creativecommons.org/licenses/by/4.0/), which permits unrestricted use, distribution, and reproduction in any medium, provided you give appropriate credit to the original author(s) and the source, provide a link to the Creative Commons license, and indicate if changes were made.

\section{References}

Adler, J. (2000). Conceptualising resources as a theme for teacher education. Journal of Mathematics Teacher Education, 3, 205-224.

Aldon, G. (2010). Handheld calculators between instrument and document. ZDM-The International Journal on Mathematics Education, 42, 733-745.

Aleven, V., McLaren, B. M., Sewall, J., van Velsen, M., Popescu, O., Demi, S., Koedinger, K. R. (2016). Example-Tracing tutors: Intelligent tutor development for nonprogrammers. International Journal of Artificial Intelligence in Education, 26(1), 224-269. doi:10.1007/s40593-015-0088-2.

Artigue, M. (2011). L'ingénierie didactique: un essai de synthèse. In C. Margolinas, M. Abboud-Blanchard, L. Bueno-Ravel, N. Douek, A. Fluckiger, P. Gibel, F. Vandebrouck \& F. Wozniak (Eds.), En amont et en aval des ingénieries didactiques (pp. 225-237). Grenoble: La pensée sauvage.

Bates, M. (2017). Leveraging tools to build deeply educative curricula for teachers: Two promising approaches. ZDM Mathematics Education. doi:10.1007/s11858-017-0868-2.

Bates, M., \& Usiskin, Z. (Eds.). (2016). Digital curricula in school Mathematics. Charlotte, NC: Information Age Publishing.

Bozkurt, G., \& Ruthven, K. (2017). Classroom-based professional expertise: A mathematics teacher's practice with technology. Educational Studies in Mathematics, 94(3), 309-328.

Brown, M. W. (2002). Teaching by design: Understanding the intersection between teacher practice and the design of curricular innovations. Unpublished doctoral dissertation. Evanston, IL: Northwestern University.

Brown, M. W. (2009). The teacher-tool relationship: Theorizing the design and use of curriculum materials. In J. T. Remillard, B. A. Herbel-Eisenmann \& G. M. Lloyd (Eds.), Mathematics teachers at work: Connecting curriculum materials and classroom instruction (pp. 17-36). New York: Routledge.

Brown, S.A., Breunlin, R.J., Wiltjer, H.M., Degner, K.M., Eddins, S.K., Edwards, M.T., \& Usiskin, Z. (2007). The University of Chicago School Mathematics Project: Algebra. (3rd Ed.). Chicago, IL: Wright Group/McGraw-Hill.

Burch, P., \& Good, A. (2014). Equal scrutiny: Privatization and accountability in digital education. Cambridge, MA: Harvard Education Press.

Chazan, D., \& Yerushalmy, M. (2014). The future of mathematics textbooks: Ramifications of technological change. In M. Stocchetti (Ed.), Media and education in the digital age: Concepts, assessments, and subversions (pp. 63-78). New York: Peter Lang.

Chesné, J.-F., Le Yaouanq, M.-H., Coulange, L., \& Grapin, N. (2009). Hélice 6e. Paris: Didier.

Choppin, J. (2016). Analysis of eight digital curriculum programmes. In M. Bates \& Z. Usiskin (Eds.), Digital curricula in school
Mathematics (pp. 161-176). Charlotte, NC: Information Age Publishing.

Choppin, J., Carson, C., Borys, Z., Cerosaletti, C., \& Gillis, R. (2014). A typology for analyzing digital curricula in mathematics education. International Journal of Education in Mathematics, Science, and Technology, 2(1), 11-25.

Choppin, J., \& Borys, Z. (2017). Trends in the design, development, and use of digital curriculum materials. ZDM Mathematics Education. doi:10.1007/s11858-017-0860-x.

Choppin, J., \& Borys, Z. (2016). Trends in the design, development, and use of digital curriculum materials. Paper presented at the 2016 American Educational Research Association Annual Meeting, Washington, $D C$.

Clark-Wilson, A. (2010). Emergent pedagogies an the changing role of the teacher in the TI-Nspire Navigator-networked mathematics classroom. ZDM-The International Journal on Mathematics Education, 42(7), 747-761.

Clark-Wilson, A., Hoyles, C., Noss, R., Vahey, P., \& Roschelle, J. (2015). Scaling a technology-based innovation: Windows on the evolution of mathematics teachers' practices. ZDM. doi:10.1007/s11858-014-0635-6.

Clark-Wilson, A., Robutti, O., \& Sinclair, N. (2014). The Mathematics teacher in the digital era: An international perspective on technology focused professional development. Dordrecht: Springer.

Confrey, J. (2016). Designing curriculum for digital middle grades mathematics: Personalized learning ecologies. In M. Bates \& Z. Usiskin (Eds.), Digital curricula in school Mathematics (pp. 7-33). Charlotte, NC: Information Age Publishing.

Confrey, J., Gianopulos, G., Shah, M., McGowan, W., \& Belcher, M. (2017). Scaffolding learner-centered curricular coherence using learning maps and diagnostic assessments designed around mathematics learning trajectories. ZDM Mathematics Education. doi:10.1007/s11858-017-0869-1.

Confrey, J., \& Maloney, A. P. (2015). A design research study of a curriculum and diagnostic assessment system for a learning trajectory on equipartitioning. ZDM, 47, 919-932.

Confrey, J., Maloney, A. P., \& Corley, A. K. (2014). Learning trajectories: a framework for connecting standards with curriculum. ZDM-The International Journal on Mathematics Education, 46(5), 719-733.

Cusi, A., Morselli, F., \& Sabena, C. (2016). Enhancing formative assessment strategies in mathematics through classroom connected technology. In C. Csikos, A. Rausch \& J. Szitanyi (Eds.), Proceedings of PME 40, vol. 2 (pp. 195-202). Szeged, Hungary: PME.

Cusi, A., Morselli, F., \& Sabena, C. (2017). Promoting formative assessment in a connected classroom environment: Design and implementation of digital resources. ZDM Mathematics Education. doi:10.1007/s11858-017-0878-0.

Davis, E., \& Krajcik, J. (2005). Designing educative materials to promote teacher learning. Educational Researcher, 34(3), 3-14.

de Araujo, Z., Otten, S., \& Birisci, S. (2017). Teacher-created videos in a flipped mathematics class: Digital curriculum materials or lesson enactments? ZDM Mathematics Education. doi:10.1007/ s11858-017-0872-6.

De Vaujany, F. -X. (2006). Pour une théorie de l'appropriation des outils de gestion: vers un dépassement de l'opposition conception-usage. Revue Management \& Avenir, 9, 1009-1126.

Doyle, W., \& Ponder, G. A. (1977). The practicality ethic in teacher decision making. Interchange, 8(3), 1-12. https://larrycuban. files.wordpress.com/2011/05/fulltext-12.pdf. Accessed 10 Apr 2017.

Drijvers, P. (2012). Teachers transforming resources into orchestrations. In G. Gueudet, B. Pepin \& L. Trouche (Eds.), From text to 'Lived' resources (pp. 265-281). New York: Springer. 
Drijvers, P., Ball, L., Barzel, B., Heid, M.K., Cao, Y., \& Maschietto, M. (2016). Uses of technology in lower secondary mathematics education: A concise Topical Survey. New York: Springer Open.

Dvir, A., \& Tabach, M. (2017). Learning extrema problems using a non-differential approach in a digital dynamic environment: The case of low achievers. ZDM Mathematics Education. doi:10.1007/ s11858-017-0862-8.

Edson, A. J. (2014). A study on the iterative development and effcacy of a deeply digital instructional unit on binomial distribution and statistical inference. Kalamazoo, MI: Western Michigan University.

Edson, A. J. (2016). A design experiment of a deeply digital instructional unit and its impact in a high school classroom. In M. Bates \& Z. Usiskin (Eds.), Digital Curricula in School Mathematics (pp. 177-203). Charlotte, NC: Information Age Publishing.

Edson, A. J. (2017). Learner-controlled scaffolding linked to openended problems in a digital learning environment. ZDM Mathematics Education. doi:10.1007/s11858-017-0873-5.

Essonnier, N., Kynigos, C., Trgalova, J., \& Daskolia, M. (2016). Studying the role of context in social creativity for the design of digital resources. 13th International Congress on Mathematics Education, Hamburg, July 2016.

Gravemeijer, K., \& Cobb, P. (2006). Design research from a learning design perspective. In J. van den Akker, K. Gravemeijer, S. McKenney \& N. Nieveen (Eds.), Educational design research (pp. 17-51). London: Routledge.

Gueudet, G., Pepin, B., Restrepo, A., Sabra, H., \& Trouche, L. (2016). E-textbooks and connectivity: proposing an analytical framework. International Journal of Science and Mathematics Education. doi:10.1007/s10763-016-9782-2.

Gueudet, G., Pepin, B., Sabra, H., \& Trouche, L. (2016). Collective design of an e-textbook: Teachers' collective documentation. Journal of Mathematics Teacher Education, 19(2-3), 187-203.

Gueudet, G., Pepin, B., \& Trouche, L. (Eds.). (2012). Mathematics curriculum material and teacher development: From text to 'lived' resources. Dordrecht: Springer.

Gueudet, G., Pepin, B., \& Trouche, L. (2013). Textbooks' design and digital resources. In C. Margolinas (Ed.), Task design in mathematics education (pp. 327-337). Oxford: ICMI Study 22.

Gueudet, G., \& Trouche, L. (2009). Towards new documentation systems for mathematics teachers? Educational Studies in Mathematics, 71(3), 199-218.

Haddif, G. H. (2017). Principles of re-designing an e-task based on a paper-and-pencil task: The case of parametric functions. Presentation at CERME 10-10th Congress of European Research in Mathematics Education, February 2017.

Herbel-Eisenmann, B. (2009). Negotiation of the "presence of the text": How might teachers' language choices influence the positioning of the textbook? In J. Remillard, B. Herbel-Eisenmann, \& G. Lloyd (Eds.), Mathematics teachers at work: Connecting curriculum materials and classroom instruction (pp. 134-151). New York: Routledge.

Keefe, J. W. (2007). What is personalization? Phi Delta Kappan, 89(3), 217-223.

Kynigos, C., \& Kolovou, A. (2016). Teachers as designers of digital educational resources for creative mathematical thinking. Presentation at the 13th International Congress on Mathematics Education, Hamburg, July 2016.

Larkin, K., \& Milford, T. (2017). Using cluster analysis to enhance student learning when using geometry mathematics apps. In C. Vale (Ed.), ICMI-13 TSG 41-The use of technology in primary school Mathematics education. Berlin: Springer (in press).

Lew, H. -C. (2016). Developing and implementing "smart" mathematics textbooks in Korea: Issues and challenges. In M. Bates \& Z. Usiskin (Eds.), Digital curricula in school Mathematics (pp. 35-51). Charlotte, NC: Information Age Publishing.
Means, B., Peters, V., \& Zheng, Y. (2014). Lessons from five years of funding digital courseware: Postsecondary Success grant portfolio review for the Bill \& Melinda Gates Foundation. Menlo Park: SRI International.

Murata, A. (2008). Mathematics teaching and learning as a mediating process: The case of tape diagrams. Mathematical Thinking and Learning, 10(4), 347-406.

Murphy, R., Gallagher, L., Krumm, A., Mislevy, J., \& Hafter, A. (2014). Research on the use of Khan Academy in schools. Menlo Park, CA: SRI Education. https://www.sri.com/sites/ default/files/publications/khan-academy-implementationreport-2014-04-15.pdf. Accessed 10 Apr 2017.

Naftaliev, E. (2016). Engagaments of prospective teachers with e-textbooks. Presentation at the 13th International Congress on Mathematics Education, Hamburg, July 2016.

Naftaliev, E., \& Yerushalmy, M. (2013). Guiding explorations: Design principles and functions of iterative diagrams. Computers in the Schools, 30(1-2), 61-75.

Nieveen, N. (2009). Formative evaluation in educational design research. In T. Plomp \& N. Nieveen (Eds.). An introduction to educational design research. http://www.slo.nl/downloads/2009/Introduction_20to_20education_20design_20rese arch.pdf. Accessed 10 Apr 2017.

Pepin, B., Gueudet, G., \& Trouche, L. (2013). Re-sourcing teachers' work and interactions: a collective perspective on resources, their use and transformations. ZDM-The International Journal of Mathematics Education, 45(7), 929-944. doi:10.1007/ s11858-013-0534-2.

Pepin, B., Gueudet, G., \& Trouche, L. (2017). Refining teacher design capacity: Mathematics teachers' interactions with digital curriculum resources. ZDM Mathematics Education. doi:10.1007/s11858-017-0870-8.

Pepin, B., Gueudet, G., Yerushalmy, M., Trouche, L., \& Chazan, D. (2016). E-textbooks in/for teaching and learning mathematics: A potentially transformative educational technology. In L. English \& D. Kirshner (Eds.), Handbook of international research in mathematics education (pp. 636-661). New York: Taylor \& Francis.

Rabardel, P. (2002). People and technology-a cognitive approach to contemporary instruments. Paris8. https://halshs.archivesouvertes.fr/file/index/docid/1020705/filename/people_and_technology.pdf. Accessed 1 Apr 2017.

Remillard, J. (2005). Examining key concepts in research on teachers' use of mathematics curricula. Review of Educational Research, $75(2), 211-246$.

Remillard, J., \& Heck, D. J. (2014). Conceptualising the curriculum enactment process in mathematics education. ZDM-International Journal on Mathematics Education, 46(5), 705-718.

Remillard, J. T. (2016). Keeping an eye on the teacher in the digital curriculum race. In M. Bates \& Z. Usiskin (Eds.), Digital curricula in school Mathematics (pp. 195-204). Charlotte, NC: Information Age Publishing.

Remillard, J. T., Herbel-Eisenmann, B. A., \& Lloyd, G. M. (2009). Mathematics teachers at work: connecting curriculum materials and classroom instruction. New York \& London: Routledge.

Rezat, S. (2013). The textbook-in-use: students' utilization schemes of mathematics textbooks related to self-regulated practicing. ZDM-The International Journal on Mathematics Education, 45(5), 659-670. doi:10.1007/s11858-013-0529-z.

Rezat, S. (2017). Students' utilizations of feedback by an interactive mathematics e-textbook for primary level. Presentation at CERME 10-10th Congress of European Research in Mathematics Education, February 2017.

Ruthven, K. (2012). The didactical tetrahedron as a heuristic for analysing the incorporation of digital technologies into classroom practice in support of investigative approaches to teaching 
mathematics. ZDM-The International Journal on Mathematics Education, 44(2), 627-640.

Ruthven, K. (2014). Frameworks for analyzing the expertise that underpins successful integration of digital technology into everyday teaching practice. In A. Clark-Wilson, O. Robutti \& N. Sinclair (Eds.), The mathematics teacher in the digital era (pp. 373-393). Dordrecht: Springer.

Ruthven, K. (2017). Instructional activity and student interaction with digital resources. Proceedings of 13th International Congress on Mathematics Education, Hamburg, July 2016. (submitted).

Ruthven, K., Deaney, R., \& Hennessy, S. (2009). Using graphing software to teach about algebraic forms: A study of technologysupported practice in secondary-school mathematics. Educational Studies in Mathematics, 71(3), 279-297.

Shute, V. J., \& Ventura, M. (2013). Measuring and supporting learning in games: Stealth assessment. Cambridge, MA: The MIT Press.

Sésamath. (2009). Le manuel Sésamath 6e. (Génération 5 ed.). Chambéry: Sésamath.

Trgalova, J., \& Rousson, L. (2017). Model of appropriation of a curricular resource: A case of a digital game for the teaching of enumeration skills in kindergarten. ZDM Mathematics Education. doi:10.1007/s11858-017-0877-1.

Trouche, L. (2004). Managing complexity of human/machine interactions in computerized learning environments: guiding students' command process through instrumental orchestrations. International Journal of Computers for Mathematical Learning, 9, 281-307.

Wiliam, D., \& Thompson, M. (2007). Integrating assessment with instruction: what will it take to make it work? In C. A. Dwyer (Ed.), The future of assessment: Shaping teaching and learning (pp. 53-82). Mahwah, NJ: Erlbaum.

Yarnell, L., Means, B., \& Wetzel, T. (2016). Lessons learned from early implementations of adaptive courseware. Menlo Park, CA: SRI International.

Yerushalmy, M. (2006). Slower algebra students meet faster tools: solving algebra word problems with graphing software. Journal for Research in Mathematics Education, 37(5), 356-387.

Yerushalmy, M. (2016). Inquiry curriculum and e-textbooks: Technological changes that challenge the representation of mathematics pedagogy. In M. Bates \& Z. Usiskin (Eds.), Digital curricula in school Mathematics (pp. 87-106). Charlotte, NC: Information Age Publishing.

Yerushalmy, M., Nagari-Haddif, G., \& Olsher, S. (2017). Design of tasks for online assessment that supports understanding of students' conceptions. ZDM Mathematics Education. doi:10.1007/ s11858-017-0871-7. 